\title{
25 Research Square \\ Effects of obesity and post-bariatric surgery weight loss on the vaginal microbiota
}

Olivia Raglan

David A. Macintyre

Anita Mitra

Yun S. Lee

Ann Smith

Nada Assi

Jaya Nautiyal

Sanjay Purkayastha

Marc J. Gunter

Hani Gabra

Julian R. Marchesi

Phillip R. Bennett

Maria Kyrgiou

\section{Video Byte}

Keywords: obesity, overweight, body mass index, BMI, vaginal microbiota, bariatric surgery, women's health, gastric bypass, gastric sleeve, Microbiome

Posted Date: October 16th, 2021

DOl: https://doi.org/10.21203/rs.3.rs-979076/v1

License: (a) (i) This work is licensed under a Creative Commons Attribution 4.0 International License. Read Full License 


\section{Abstract}

Obesity is a prevalent problem worldwide with major health effects. In addition to overall effects, obesity can cause a wide array of gynecological and obstetric complications in women. Because shifts in the vaginal microbiota (VMB) can also be a risk factor for adverse reproductive and health outcomes, researchers examined the relationship between the VMB and obesity. Using sequencing to assess the microbiota in 67 obese women, 42 non-obese women, and 27 women who underwent bariatric surgery, they found a lower prevalence of Lactobacillus and higher prevalence of high-diversity species in the $\mathrm{VMB}$ of obese subjects. Local vaginal levels of many inflammatory cytokines were also elevated in obese women, but only IL-1 $\beta$ and IL-8 levels were correlated with VMB diversity. The VMB did not change significantly within 6 months of bariatric surgery, but many womens' BMls also remained within the obese range during that time. Post-surgery, women with a Lactobacillus-dominant VMB had significantly lower BMls than those with a diverse VMB. These results provide novel insight into the relationship between weight, VMB, and reproductive health. 